\title{
Comentarios
}

\section{A propósito de la "polarización"}

El proceso político salvadoreño, aun y con ser en sus tendencias fundamentales marcadamente predecible, plantea algunos desafíos para la cabal comprensión de sus dinamismos más importantes. Uno de estos desafíos - puesto en la mesa de discusión cada vez que se sucede una coyuntura electoral- es el de la tan debatida "polarización", asociado directamente con el problema del "centro político" y su viabilidad. En estas reflexiones queremos volver sobre el tema, más con ánimo de poner por escrito las propias incertidumbres que para establecer tesis firmes sobre la materia. Sabedores de que en la comprensión de los procesos histórico-políticos difícilmente se pueden establecer verdades definitivas e indiscutibles, es preferible y razonable dar al propio discurso un carácter meramente hipotético, abrigando el deseo —en el mejor espiritu popperiano- de que las hipótesis formuladas, lejos de ser ciertas, revelen sus debilidades más profundas. Sin duda alguna, quien las encuentre merecerá todos los créditos, pero no deberá olvidar que sus propias formulaciones serán también sólo unas conjeturas, a lo sumo mejor fundadas, pero conjeturas que, en cuanto tales, estarán sujetas a la discusión y a la revisión críticas.

Ante todo, es pertinente - como enseña la tradición de la filosofía analítica- aclarar el alcance del término en discusión. Esta aclaración es tanto más necesaria en cuanto que palabras como "polarización" no sólo tienen una carga semántica particular, sino que son usadas por distintas personas - periodistas, analistas, académicos, políticosen distintas circunstancias y no siempre con idéntico sentido. Pasemos, pues, a la revisión del término "polarización".
Lo primero es lo primero: vayamos al Diccionario del español actual, de Manuel Seco (Madrid, Aguilar, 1999). Seco nos dice lo obvio: polarización es la "acción de polarizar". Y añade lo siguiente sobre la expresión, tal como es usada en el marco de la ciencias naturales: "polarización de la luz. Al incidir la luz en un cuerpo anisótropo, se desdobla el rayo incidente en dos refractados". De la misma expresión, usada en un contexto histórico, dice: "en la juventud española se nota una escasa polarización hacia esas nuevas preocupaciones universales". Para aclararnos más, siempre siguiendo a Seco, tenemos que revisar el vocablo "polar", pues la polarización lo presupone. Lo polar tiene que ver, primero, con los polos de la tierra, es decir, con las zonas polares. En segundo lugar, tiene que ver con un fenómeno eléctrico: dos cargas opuestas, lo cual da lugar a una polaridad eléctrica. De esta acepción deriva una tercera, que es la de "totalmente opuesto". Puesto en un contexto: "existe incompatibilidad rigurosa, oposición humoral y polar entre la avenencia a la derrota y la ocupación consumadas y el designio de fortalecer y garantizar por la acción de las armas los derechos de la metrópoli a su soberanía en Argelia" (p. 3598).

Hasta aquí con el Diccionario del español actual. Lo que sacamos en limpio, de momento, es que en la acción de polarizar existen dos polos totalmente contrarios. Para aclarar más el término, veamos otro diccionario: el Diccionario de políti$c a$, preparado por Norberto Bobbio, Nicola Matteucci y Gianfranco Pasquino (México, Siglo XXI, 1998): ni la palabra "polar" ni la palabra "polarización" aparecen registradas. Consultemos otro diccionario: el Diccionario político de Eduardo 
Haro Tecglen (Barcelona, Planeta, 1995): tampoco aquí aparece registrado el término, cuya definición buscamos'. Salgamos de la política y vayamos a la filosofía, concretamente al imprescindible Diccionario de filosofía de Nicola Abbagnano (México, FCE, 1987). Abbagnano registra la palabra "polaridad", de la cual - siguiendo a Schellingdice lo siguiente: "la relación necesaria de dos principios opuestos entre sî". Según Abbagnano, ese es el sentido que da al término, en la filosofía contemporánea, Morris S. Cohen, quien entiende por polaridad "el principio de no identidad sino de la presencia simultánea y necesaria, y de la dependencia recíproca entre las determinaciones opuestas" (p. 926). Desde la filosofía, pues, se añade un matiz al problema de la polarización: los polos opuestos están en una relación de dependencia recíproca. Es decir, cada uno de ellos se constituye como tal en relación simultánea con el otro.

Dejemos ahora a un lado los diccionarios ${ }^{2}$ y remitámonos a un escrito breve pero denso de Ignacio Martín-Baró: "Polarización social en El Salvador" (ECA, 412, 1983, pp. 129-142). En este artículo, desde el aparato conceptual de la psicología, Martín-Baró utiliza el término "polarización" para el análisis de la realidad social: "entendemos aquí por polarización aquel proceso psicosocial por el cual las posturas ante un determinado problema tienden a reducirse cada vez más a dos esquemas opuestos y excluyentes al interior de un determinado ámbito social. Se da polarización social cuando la postura de un grupo supone la referencia negativa a la postura de otro grupo, considerado como su rival. Se trata, por tanto, de un fenómeno dinámico, un proceso de fuerzas sociales donde el acercamiento a uno de los polos arrastra no sólo el alejamiento, sino el rechazo activo del otro... La polarización social es por esencia un fenómeno grupal que ocurre sobre el trasfondo de una sociedad escindida en clases y que involucra la elaboración ideológica de unos intereses sociales" (p. 130).

Martín-Baró mantiene el sentido de la expresión acuñado por Manuel Seco: en la polarización tenemos dos esquemas - polos- opuestos y excluyentes. En el plano social, dice Martín-Baró, esos esquemas son posturas de un grupo "referidas negativamente" a las posturas de otro grupo. Aquí nuestro autor introduce una novedad: a nivel social, la polarización supone una referencia negati$v a$ entre los polos; supone una mutua negación. Otra novedad: se trata de un fenómeno dinámico, es decir, de un proceso mediante el cual acercarse a uno de los polos exige alejarse y rechazar activamente al otro. Por consiguiente, alejamiento y rechazo activo, práctico. Pero también, tercera novedad, ideológico, puesto que la polarización "involucra la elaboración ideológica de unos intereses sociales".

Como podemos ver, con Martín-Baró no se pierde el sentido de "polarización" como la existencia de dos polos opuestos e interdependientes entre sí. Además, él enriquece la noción, al llevarla al ámbito social, con las siguientes precisiones: los dos polos están conformados por grupos sociales, refereridos negativamente entre sí -esto es, que la afirmación de uno de ellos exige la negación del otro-, dinámica y activamente opuestos y sustentados por elaboraciones ideológicas. Desde esta perspectiva, vislumbrar una situación de polarización social supone, primero, detectar la presencia de dos grupos claramente delimitados entre sí; segundo, que esos grupos estén referidos negativamente uno al otro; tercero, que se rechacen activamente; $y$, cuarto, que ese rechazo se sustente en una elaboración ideológica.

Evidentemente, se puede objetar que la idea de polarización manejada por Martín-Baró surgió en un clima de enfrentamiento armado y que es en

1. Ciertamente, que una palabra no aparezca en un diccionario no quiere decir que no sea importante o que no sea ampliamente usada. Igual, que una palabra aparezca en un diccionario con una acepción determinada no quiere decir que esa acepción sea la mejor, la única o la más común. Pero también es claro que hay diccionarios y diccionarios, y que si una palabra aparece en los más serios de ellos —como el de Manuel Seco- con un sentido determinado, por algo será. Por lo mismo, si una palabra no aparece en un diccionario serio - como sucede con la palabra "polarización" en el diccionario de política de Bobbio, Matteucci y Pasquino- puede ser por, al menos, tres razones: que a juicio de los autores no sea parte del aparato conceptual de la ciencia política; que tenga una sentido poco riguroso (ambiguo o confuso) en quienes la usan en ese campo del saber; o que los autores no estén actualizados o hayan padecido un lapsus imperdonable.

2. A propósito de diccionarios, también hemos revisado, sin éxito, el Diccionario de sociología de Luciano Gallino (México, Siglo XXI, 1992): no está registrada la palabra "polarización". 
ese contexto que adquiere sentido la acepción que él da al término. Es preciso aclarar esto. Ciertamente, Martín-Baró utiliza la idea de polarización en un contexto de enfrentamiento armado, pero el término ni se agota en su referencia a un enfrentamiento armado - aunque quizás ese tipo de enfrentamiento sea el que exprese más nítidamente una situación de polarización-, ni ha sido utilizado únicamente para caracterizar una situación en la que existen dos bandos militares, que buscan eliminarse mutuamente. De hecho, Martín-Baró, en el artículo que comentamos, señala cómo la tesis del etnocentrismo (formulada por Willian Summer ${ }^{3}$ en 1906), apunta en un esquema de polarización social, al igual que lo hace la teoría de los estereotipos (formulada por Henri Tajfel ${ }^{4}$ en 1981).

Dicho de otro modo, el concepto de polarización puede ser usado para caracterizar una situación de enfrentamiento armado - quizás porque es el que mejor sirve para avanzar en la comprensión de la dinámica grupal que la caracteriza-, pero no se agota en -ni se restringe a- su referencia a esa situación. En una situación de guerra civil, hay polarización porque hay enfrentamiento entre dos bandos (polos), que se niegan mutuamente, tanto en el plano práctico como en el plano ideológico. No es cierto, entonces, que porque hay enfrentamiento militar es que hay polarización, como si esta última fuera una derivado del primero y nada más. Así, pues, es razonable pensar que existen situaciones de polarización distintas al -y quizás más atenuadas que - el enfrentamiento militar.

Ahora bien, para que el sentido del término no se pierda —l sentido que se ha perfilado en nuestra discusión-, alli donde se detecta "polariza- ción" (social o política) lo fundamental que se le adscribe a esta palabra no debe faltar: deben existir dos polos, mutuamente referidos entre sí de un modo negativo, cada uno de los cuales se afirma a si mismo a través del rechazo activo e ideológico del otro $\sigma^{5}$. Es indudable que la palabra puede ser usada en otro sentido, incluso opuesto al que hemos planteado hasta aquí. Y ello quizás con tanta legitimidad -aunque no con más legitimidadcomo la de quienes prefieren la acepción registrada por Manuel Seco y utilizada por Martín-Baró, en su artículo sobre la polarización social en El Salvador. Al fin y al cabo, no sería la primera vez que una palabra adquiere varios sentidos, algunos de los cuales pueden ser contradictorios; lo cual puede conducir a que, al ser usada por dos interlocutores, lo que uno de ellos niega y el otro afirma pueda, en definitiva, ser lo mismo.

La palabra "subjetivo" - por no insistir en términos como "democracia" o "ideología"- es un buen ejemplo de lo anterior: lo "subjetivo" se opone a lo "objetivo" y, normalmente, se entiende por "objetivo" algo real, algo que está fuera de la mente humana (fuera del sujeto) y que no depende de ella. Decimos que es lo objetivo por oposición a lo subjetivo. En la tradición filosófica, como nos hace saber Xavier Zubiri (El hombre y la verdad, Madrid, 1999), las cosas no han sido tan claras. Para los medievales, "lo más real de una cosa, lo que propiamente constituye su inexorable realidad física, es su momento de subjetualidad, su momento de ser sujeto" (p. 126). En la filosofía moderna, hace notar Zubiri, se produce un cambio en el término: "la única realidad subjective es precisamente el sujeto humano. Y lo objective es justamente algo que no hace sino estar meramente pre-

3. Willian Summer, Las costumbres tradicionales, New York, Ginn, 1906.

4. Henri Tajfel, Los grupos humanos y las categorías sociales: estudios en psicología social, Cambridge, Cambridge University Press, 1981.

5. Ya redactadas estas páginas, dando un vistazo al libro de Giovanni Sartori, Partidos y sistemas de partidos (Madrid, 1997) encontramos lo siguiente sobre la polarización: "si un sistema político contiene oposiciones antisistema, bilaterales y desalienta... la competencia centrípeta, estos rasgos llevan a un sistema polarizado... Lo que persiste es que en todos los casos el espectro de la opinión pública está muy polarizado: sus polos laterales están literalmente a dos polos de distancia y la distancia entre ellos abarca el espectro máximo posible de opinión. Esto equivale a decir que lo más probable es que las fisuras sean muy profundas, que, sin duda, un consenso es muy escaso y que son muchos quienes ponen en duda la legitimidad del sistema político. En resumen, hay polarización cuando hay distancia ideológica (en contraposición a la proximidad ideológica)" (pp. 169-170). Esta idea se plantea en el contexto de lo que significa, para Sartori, el "pluralismo polarizado", el cual tiene las siguientes características: presencia de partidos anti-sistema importantes, existencia de oposiciones bilaterales, ubicación en el centro político de uno o varios partidos, existencia de dos polos distanciados ideológicamente, prevalencia de impulsos centrífugos sobre los centrípetos, estructuración ideológica congénita, oposiciones irresponsables y existencia de promesas excesivas (pp. 165-175). 


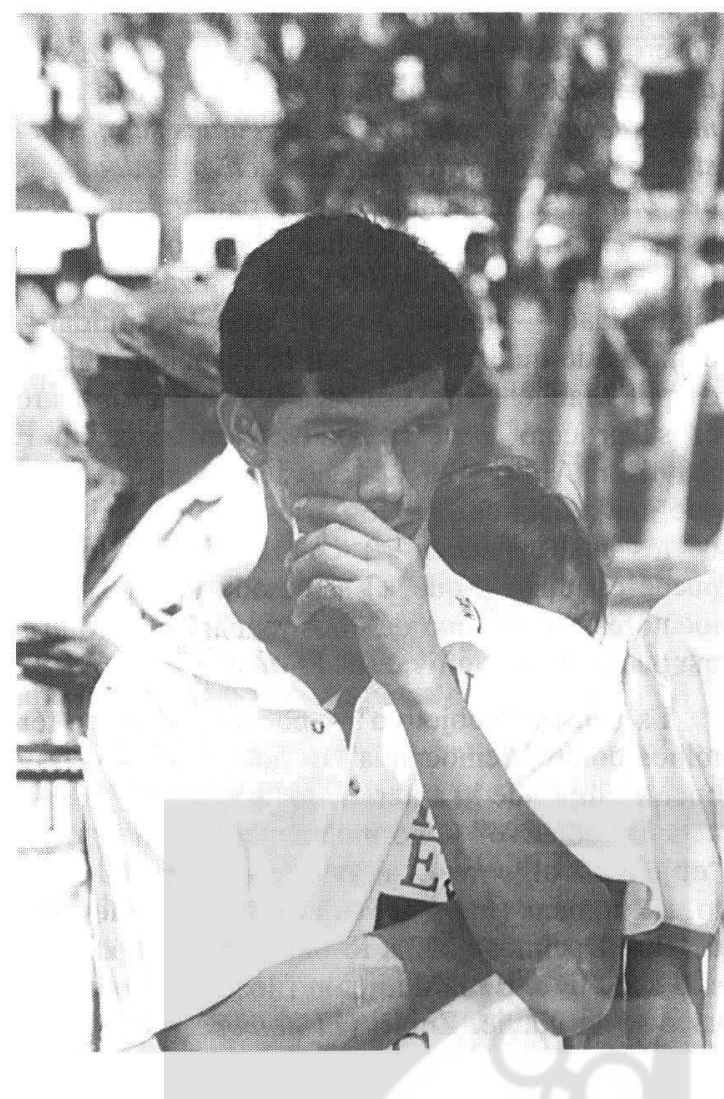

sente en el intelecto" (p. 127). De modo que si se usa la expresión "subjetivo" en la acepción que le dieron los medievales, nos estamos refiriendo a lo más real de una cosa; si se usa en el sentido moderno, nos referimos al cogito, al yo que piensa.

Por lo mismo, en sentido medieval de la formulación "la realidad es subjetiva" es equivalente al sentido de la formulación moderna "la realidad no es subjetiva". Ambas apuntan a lo mismo: a que la realidad es, en esencia, algo físico. Y lo mismo sucede con la palabra "objetivo": para un escolástico, lo "objetivo" es lo pensado en cuanto pensado, mientras que para un moderno es lo real presente en el intelecto humano. Así, la formulación escolástica "santo Tomás rechaza solamente las afirmaciones objetivas" viene a coincidir con la formulación moderna "santo Tomás acepta solamente las afirmaciones objetivas". Y se entiende: en los tiempos medievales rechazar las afirmaciones objetivas era rechazar los juicios que no se referían al sustrato físico-natural de la realidad; en los tiempos modernos, por el cambio en el significado del término "objetivo", aceptar los juicios objetivos significa aceptar aquellos juicios que se remiten a la realidad física (presente en el intelecto).

Lo anterior es sólo para dejar establecido que las palabras cambian y que esos cambios pueden hacer que ellas adquieran incluso significados opuestos. ¿Ha sucedido eso con la palabra "polarización"? ¿Se trata, acaso, de que existen quienes la usan en el sentido registrado por nosotros y otros que la usan en un sentido opuesto? ¿Será que, en virtud de ese posible cambio semántico, cuando unos dicen "polarización" se refieren a la existencia de dos polos que se excluyen mutuamente, mientras que otros, usando la misma palabra, se refieren a la inexistencia de esos dos polos? ¿Es posible que haya una coincidencia entre quienes dicen "no hay polarización en El Salvador" y los que dicen "hay polarización en El Salvador? Puede ser; después de todo, como hemos dicho antes, no sería la primera vez que una palabra cambia de sentido.

Ahora bien, también es probable que no se trate de una trampa semántica, sino de un problema de percepción de la realidad social: puede que quienes no vean polarización en un contexto sociopolítico concreto - ya sea por falta de lucidez o ignorancia-, no alcancen a ver una situación caracterizada por la presencia de dos grupos que se niegan mutuamente a nivel práctico e ideológico, mientras que los que sí ven polarización - ya sea por su lucidez y sus conocimientos-, en ese mismo contexto vean dos polos enfrentados entre sí con ideas, programas y actitudes, las cuales no admiten los arreglos intermedios ni las soluciones de compromiso (de lo contrario, no serían dos polos). Situada la discusión en El Salvador es claro que abundan quienes proclaman a viva $\mathrm{voz}$ - sobre todo desde algunos círculos políticos - la existencia de una dinámica política de polarización. Si están usando el término en el sentido "normal" (que nosotros hemos registrado), es claro que ven un ambiente político dominado por la presencia de dos polos políticos (el FMLN y ARENA), que se niegan mutuamente, tanto en el plano práctico como en el plano ideológico. Las otras tres posibilidades son: que usen el término en un sentido opuesto al "normal"; que lo estén usando mal o que su percepción de lo que sucede sea equivocada.

Algo parecido puede decirse respecto de los que afirman "en El Salvador no hay en la actualidad una situación de polarización sociopolítica". 
En estos es claro el uso del término en su acepción "normal". Y es probable que le atinen cuando insisten en que no ven en el contexto sociopolítico salvadoreño dos polos (el FMLN y ARENA), afirmándose a sí mismos mediante el rechazo, activo e ideológico, mutuo. Pero también es probable: (a) que se equivoquen en su percepción de la realidad; puede que no vean - que no quieran ver- lo que todo el mundo ve: dos bandos políticos entre los cuales no existe la más mínima posibilidad de acercamiento práctico o ideológico, sino más bien lo contrario: el rechazo por todos los medios a su alcance; y $(b)$ una segunda probabilidad es que quienes no perciben una situación de "polarización" en El Salvador estén usando mal la palabra, por no estar al tanto de los últimos matices adquiridos por la misma, en el quehacer sociopolítico. Puede que no se hayan enterado de que la palabra ya no significa enfrentamiento y rechazo práctico e ideológico entre dos polos, sino algo bien distinto al uso corriente del término.

¿Por cuál de las dos posiciones habrá que decidirse? Bueno, pues por la que cada uno considere más razonable, a sabiendas de que, en principio, ninguna de ellas tiene el patrimonio de la verdad absoluta: ambas son totalmente discutibles en sus supuestos y sus conclusiones de fondo. Pensar lo opuesto es pecar de una arrogancia imperdonable, por ser contraria al espíritu que debe animar la búsqueda sin término de la verdad histórica, social y política.

¿Qué puede aportar la discusión anterior al tema del "centro político" en El Salvador? Pues bien, lo primero que hay que decir es que, en general, es ampliamente aceptado que en El Salvador el centro político tiene dificultades para implantarse como un proyecto con un perfil no sólo definido, sino políticamente viable. El desacuerdo aparece cuando se indaga sobre las razones de ello. Hay quienes sostienen que el centro político es inviable debido a la existencia de una situación política polarizada, la cual impide, al ocupar el espacio político, que se perfile una alternativa a los polos contrapuestos. Una segunda opinión parece sugerir lo contrario: que debido a la inexistencia de unos polos claramente definidos, es dificil que un proyecto de centro pueda constituirse, dado lo problemático que resulta deslindarse ideológica y prácticamente (adquirir un perfil propio) ante dos partidos no totalmente equidistantes. Es curioso, pero la misma palabra "centro" sólo tiene sentido en relación a dos puntos extremos. Si esos puntos extremos no existen o se aproximan lo suficiente, ¿cómo se va a constituir un centro equidistante de ellos? A lo sumo, ellos mismos se convertirán en una especie de "centro", pero por convergencia entre ambos ${ }^{h}$.

En cualquier caso y dejando a un lado la terminología, no puede descartarse apriorísticamente una de las interpretaciones en favor de la otra. Ambas son razonables y la elección de una u otra dependerá, en buena medida, de si se acepta la existencia o no de una situación de polarización política en El Salvador. Y es que mientras que la primera interpretación explica la debilidad del centro político por la vigencia de una situación de polarización, la segunda explica esa misma debilidad por la ausencia de una situación de polarización. Entre tanto, mientras el debate intelectual avanza en el tema, es seguro que los políticos que abanderan una propuesta de centro continuarán insistiendo en que en el país hay una grave situación de polarización, que justifica su proyecto político.

Para su supervivencia parece ser imprescindible que haya polarización; si no fuera así, no insistirían tanto en el asunto. Con su actilud, desmienten a los que creen que la polarización es un obstáculo para la constitución de un centro político. Lo más probable, claro está, es que estos políticos no sepan bien qué es lo que les conviene; que no sepan que mientras haya polarización no tendrán oportunidad alguna para sacar adelante su proyec-

6. De hecho, hay razones de sobra para sostener el argumento de una "convergencia" práctica e incluso ideológica entre ARENA y el FMLN en temas fundamentales, con lo cual ambos partidos no sólo diluyen su presunta polaridad, sino que tambićn terminan por sacar adclante iniciativas políticas, cconómicas y socialcs que correspondería llevar adelante a un grupo político de centro. A modo de hipótesis se puede sostener que en muchos aspectos, ARENA y el FMLN ocupan el espacio del centro, con lo cual quienes quieren ocuparlo no tienen nada factible que ofrecer. Quizás una revisión a fondo tanto de la aclividad lcgislativa de ambos parlidos, así como de sus plataformas políticas últimas ayudaría a aclarar esas convergencias a las que hacemos alusión. Y no hay que perder de vista que la polarización, en el sentido "normal" del término, excluye cualquier convergencia — práctica o ideológica - entre los polos respectivos. 
to como algo realmente alternativo a las ofertas cada vez más difusas de la izquierda y de la derecha. Como dice Alain Touraine, tras un reflexión de conjunto sobre América Latina, "es urgente que la vida política vuelva a polarizarse, que se enfren- ten programas que representen alternativas reales, lo que no quiere decir que renazca el espíritu revolucionario"?.

\section{Luis Armando González}

7. Alain Touraine, "La debilidad del centro", El País Digital, 1 de abril de 2000. 